\title{
OPEN Integrating large mammal behaviour and traffic flow to determine traversability of roads with heterogeneous traffic on a Central Indian Highway
}

\begin{abstract}
Akanksha Saxena, Nilanjan Chatterjee, Asha Rajvanshi \& Bilal Habib ${ }^{\bigotimes}$
Roads impact wildlife in multiple ways, most conspicuous amongst which are animal-vehicle collisions (AVCs). Mitigation measures to reduce AVCs at the local scale are often centred on speciesspecific crossing zones and collision hotspots. However, at the road network scale, consideration of interactions among road, species and traffic characteristics influencing AVC occurrence is required to design effective mitigation strategies. We modelled traversability-the probability of an animal successfully crossing a road- across an Indian highway for six large mammal species under different scenarios of road and traffic characteristics. Among the study species, group-living and slow-moving animals had higher AVC probabilities that increased significantly with increasing traffic volume and proportions of heavy vehicles in the traffic flow. The risk of AVC was higher for species that were active near roadside habitat during peak traffic hours. Our approach could help identify roads that pose potential mortality risks to animals using empirical data on animal and traffic characteristics. Results suggest that regulating traffic volume and heterogeneity on existing road stretches could potentially reduce animal mortality and barrier effect. Mitigation on roads expected to carry heavy traffic loads passing through ecologically-sensitive areas should be prioritised to ensure traversability for animal communities.
\end{abstract}

The transportation infrastructure of a nation is vital for its social and economic growth, especially for a developing economy. However, the construction and operation of roads come at great costs to wildlife and forests dissected by linear infrastructure ${ }^{1,2}$. The most conspicuous impact of roads is wildlife-vehicle collisions, which is a major cause of decline in animal populations in human-dominated landscapes ${ }^{3}$. Road-related mortality affects animal populations more adversely than natural mortality since it is non-selective, and affects healthy and unhealthy individuals of a population equally ${ }^{4,5}$.

Roads also cause some species to respond by avoidance of habitat near high traffic roads at peak traffic hours $^{6,7}$. This avoidance of roadside habitat could result in the road becoming a barrier to animal movement ${ }^{8}$. In addition to the risk of local species extinction ${ }^{9}$, mortality and barrier effects together alter wildlife movement ${ }^{10,11}$ leading to isolation of populations ${ }^{12,13}$. With the global road network growth projected at more than $60 \%{ }^{14}$, and rampant increase in worldwide vehicle ownership ${ }^{15}$, these impacts are set to accelerate in magnitude.

Variations in roadkill rates among species have been attributed to various environmental and species-specific features such as age group or life history stage ${ }^{16-19}$, sex and diet ${ }^{20,21}$, and animal activity patterns ${ }^{6,22}$. Therefore these traits are critical for identifying species most vulnerable to mortality and barrier effects for effective mitigation. Environmental and landscape features such as food resource distribution and habitat type ${ }^{20,21}$, and roadrelated features like traffic volume, vehicle speed, road width and road type $\mathrm{e}^{21,23-27}$ also affect roadkill rates. Large traffic volumes may reduce the frequency of attempted crossings ${ }^{7,22}$, leading to low roadkill numbers, and could also cause the road to become a physical barrier to animal movement ${ }^{28-31}$.

Mitigation of roadkill and barrier effects of rapidly expanding road networks requires identification of road sections that may cause animal mortalities and barriers to animal movement, and species most likely to be involved in $\mathrm{AVCs}^{8}$. Studies that take into account road, traffic and landscape characteristics along with species presence, activity and movement characteristics ${ }^{8,25,32}$ have been able to predict mortality and barrier hotspots 


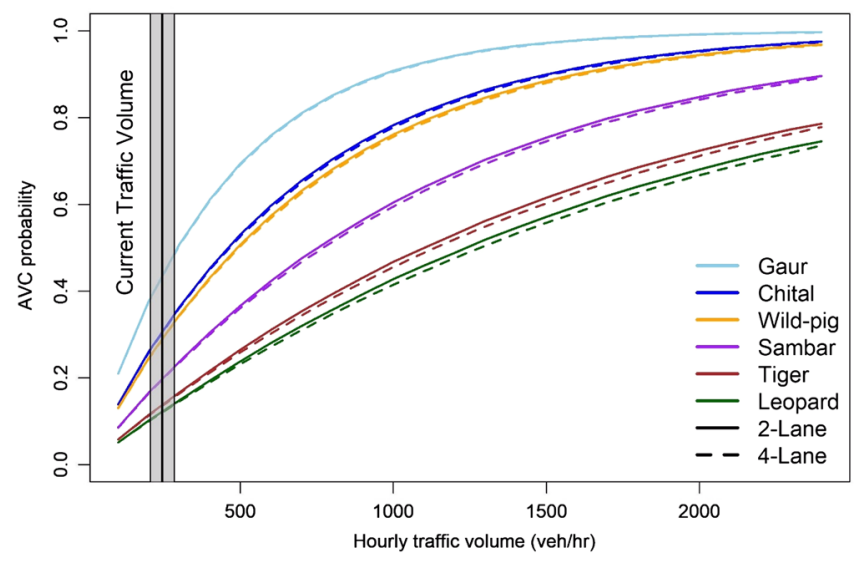

Figure 1. Animal Vehicle Collision probabilities with increasing hourly traffic volume (projected) at present traffic heterogeneity conditions on 2-lane (solid lines) and 4-lane (dashed lines) sections of the National Highway 44, passing through the Pench Tiger Reserve, India. Figure created using $\mathrm{R}^{45}$ version 3.6 (https://www. rstudio.com/).

across road networks. However, the interaction among risk factors contributing to roadkill and barrier effects to inform mitigation strategies is largely missing from such models. Moreover, mitigation for rapidly expanding road networks should also be informed by road and traffic characteristics such as road types, and projections of traffic growth ${ }^{33}$ and traffic composition or 'heterogeneity' that is the proportion of different vehicle types in a traffic flow ${ }^{8}$.

We present a framework to identify species and roads vulnerable to AVC as a function of road, traffic and species characteristics, using data from traffic simulations under different traffic heterogeneity and volume scenarios, and morphometry and behavioural data of six widespread large mammals of Central India. The study was conducted on a $60 \mathrm{~km}$ stretch of the National Highway 44 (NH 44) passing through the Pench Tiger Reserve (PTR) in Madhya Pradesh and Maharashtra states.

We sought to answer four questions: (1) which species traits increase AVC probability (defined as the probability of an animal colliding with a vehicle while crossing a road, and is to be interpreted as the opposite of traversability)? (2) Which road and traffic characteristics make roads less traversable (i.e. increase AVC probability) for animal movement? (3) At what traffic volumes and compositions do roads become barriers for animal movement? (4) Does animal activity near roads increase AVC risk (defined as the hourly AVC probability as a function of animal activity)?

We hypothesised that slow-moving and group-living animals would have greater AVC probabilities under fast-moving highly heterogeneous traffic conditions. Additionally, we hypothesised that animals with high activity overlaps with traffic would have greater AVC risk.

\section{Results}

Influence of species traits on AVC probability. Among the six study species, group-living species (gaur, chital, wild pig, sambar) had the highest AVC probabilities under hourly traffic volumes ranging between 100 and 2400 vehicles/h with present traffic heterogeneity (61\% car, 13\% bus/truck, and 26\% MAVs) on NH44 (Fig. 1). Under present traffic heterogeneity and average hourly traffic volume $(245 \pm 20$ vehicles/h) on NH44, lowest average daily AVC probabilities were found for tiger $(0.13 \pm 0.05)$ and leopard $(0.11 \pm 0.04)$ (Fig. 1). Chital $(0.29 \pm 0.10)$ and wild pig $(0.29 \pm 0.20)$ had similar average daily AVC probabilities, while sambar $(0.42 \pm 0.13)$ had a lower AVC probability among ungulates. Across both lane types, gaur had the highest average daily AVC probability.

We found that an increase in group size increased the probability of hit (species length PIC $0.003 ; 95 \%$ CI $0.001-0.005)$ while increasing animal velocity decreased the probability of hit (PIC $-0.005 ; 95 \% \mathrm{CI}-0.011$ to -0.002). Animal width did not influence AVC probability significantly (PIC 0.04; 95\% CI - 0.043-0.1) (Fig. 2).

Influence of road and traffic characteristics on AVC probability. The average daily traffic volume on $\mathrm{NH} 44$ during the study period was $5883 \pm 168$ vehicles, while the average hourly traffic volume was $245 \pm 20$ vehicles/h, comprising of $61 \%$ car, $13 \%$ bus/truck, and $26 \%$ MAVs. Simulations for present traffic heterogeneity on NH 44 at different hourly traffic volumes showed that heavy vehicles (MAVs) had the lowest, and lighter vehicles viz., cars had the highest free flow speeds within a traffic flow (Fig. 3).

For simulated heterogeneity scenarios at different hourly traffic volumes, the average harmonic traffic flow speeds of homogeneous traffic scenarios were higher than that of heterogeneous scenarios with greater proportions of heavy vehicles. Results of the traffic flow speed simulation under different heterogeneity scenarios have been provided in Supplementary Figure S1.

Across all simulated traffic heterogeneity scenarios, the AVC probability $\left(P_{h}\right)$ for all species increased with increase in traffic volume and showed similar variation among species as under present traffic heterogeneity. 

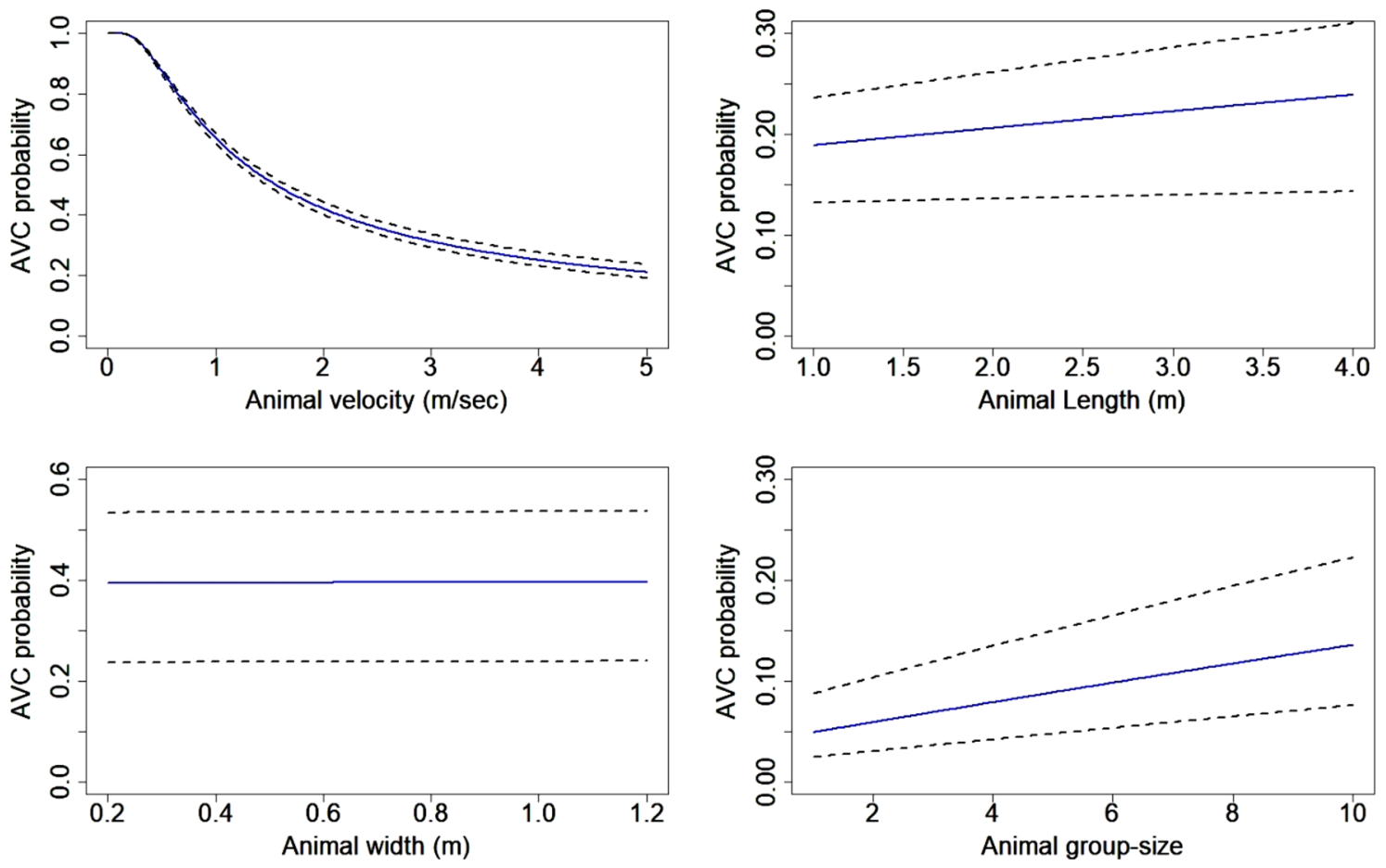

Figure 2. Relative effects of species traits on Animal Vehicle Collision (AVC) probability. To calculate the change in AVC probability with unit change in the target variables, the mean values of other variables were plugged into Eq. (1). Dotted lines indicate $95 \%$ confidence intervals around coefficient estimates. Figure created using $\mathrm{R}^{45}$ version 3.6 (https://www.rstudio.com/).

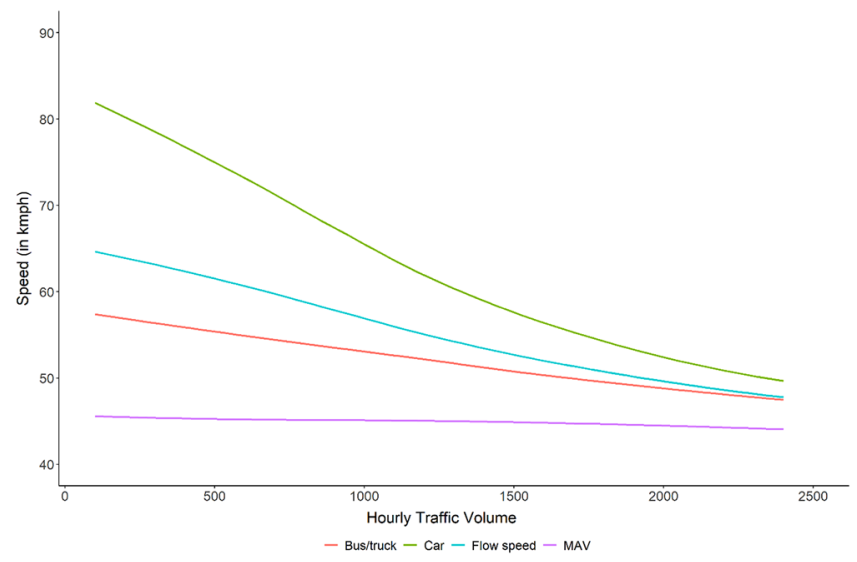

Figure 3. Simulated average harmonic traffic flow speed of present heterogeneity $\mathrm{H}_{0}$ (blue curve) on $\mathrm{NH} 44$ at different traffic volumes, and free flow speeds of different traffic components viz., car (green), Bus/truck (red) and MAV (purple) in the same simulation. Figure created using $\mathrm{R}^{45}$ version 3.6 (https://www.rstudio.com/).

All animals had high $P_{h}$ for traffic mostly comprising of heavy vehicles (scenarios $\mathrm{H}_{3}, \mathrm{H}_{5}, \mathrm{H}_{6}$ ) while low $P_{h}$ was observed for scenarios where traffic mostly composed of light vehicles $\left(\mathrm{H}_{0}, \mathrm{H}_{1}\right)$ (Fig. 4).

The threshold traffic volume at which AVC probability was equal to probability of successful crossing $\left(P_{h}=0.5\right)$ varied for different species. Under present traffic heterogeneity, this threshold traffic for group living animals like chital, gaur and wild pig was 300-400 vehicles/h. This threshold traffic volume was higher for sambar (700 vehicles/h), and highest for tiger and leopard (1100-1300 vehicles/h). Across all simulated scenarios, traffic volumes of 200-300 vehicles/h decreased the chances of a successful crossing by half for gaur. For chital, this traffic volume lies above $400-500$ vehicles/ $h$ in traffic composed of light vehicles $\left(\mathrm{H}_{0}, \mathrm{H}_{1}, \mathrm{H}_{4}, \mathrm{H}_{7}\right)$. This threshold volume is higher for sambar $\left(1100\right.$ vehicles/h) in traffic composed mostly of heavy vehicles $\left(\mathrm{H}_{3}, \mathrm{H}_{5}, \mathrm{H}_{6}\right)$. Hourly traffic volumes above 1000 vehicles/h posed a barrier to $<50 \%$ successful traverses for tiger and leopard at most traffic heterogeneity scenarios. The threshold traffic volume for solitary species was lowest (800 vehicles/h) at 


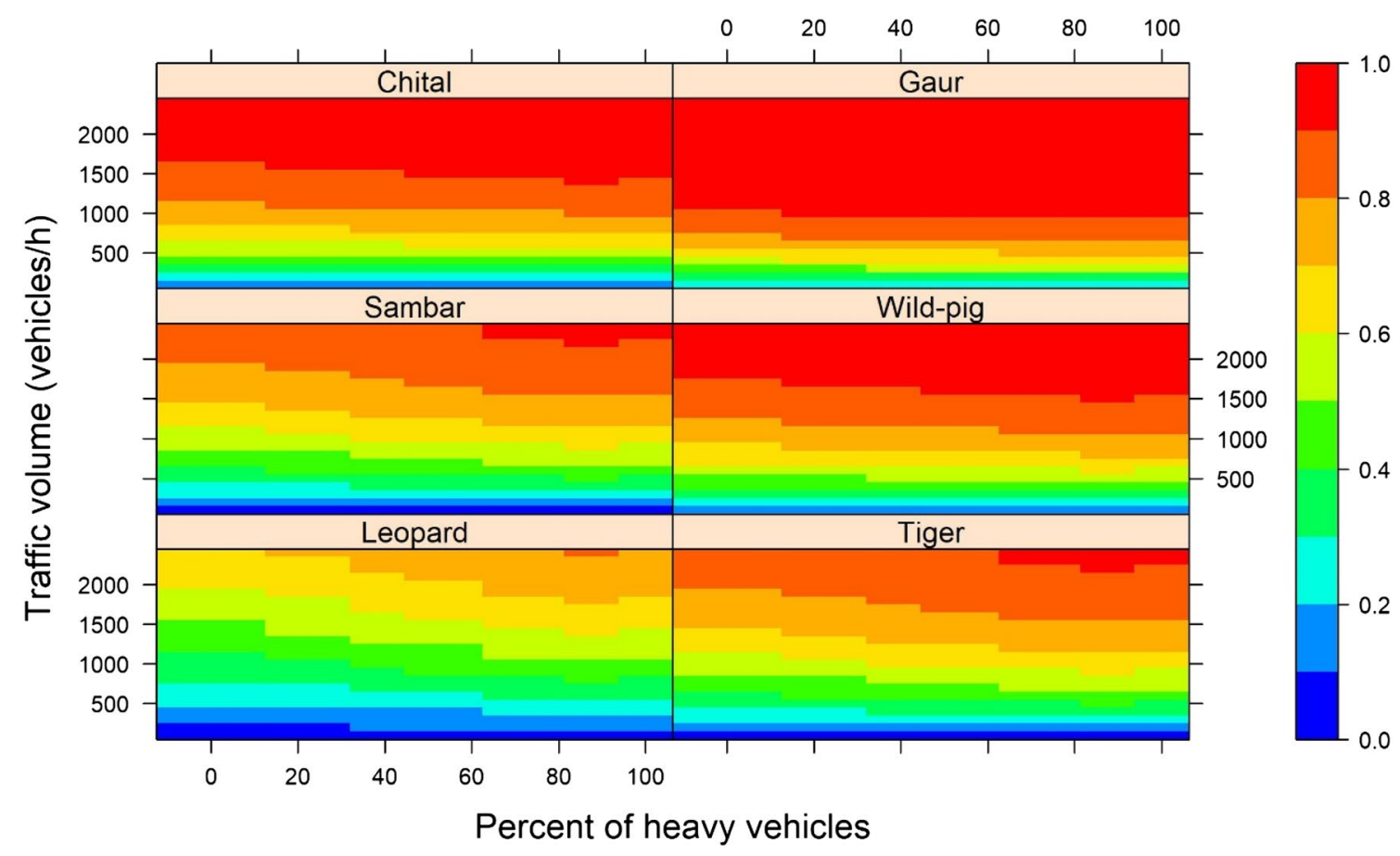

Figure 4. Gradient of Animal Vehicle Collision (AVC) probability for six study species across increasing traffic volumes under different percentages of heavy vehicles (representative of different heterogeneity scenarios). Colour bar to the right of plots depicts AVC probability $\left(P_{h}\right)$. Figure created using package 'lattice'58 in $\mathrm{R}^{45}$ version 3.6 (https://www.rstudio.com/).

scenario $\mathrm{H}_{3}$ which comprised of only MAVs. Beyond this threshold traffic volume, higher fatalities are expected to occur.

For all study species, we found that the time on the road during which an animal is vulnerable to AVC (expressed as AVC exposure in seconds) was almost double (197.94\% \pm 1.72$)$ on 4-lane segment as compared to 2-lane segment at the same traffic volumes (at present traffic heterogeneity) (Fig. 5). For chital, gaur and wild pig, AVC exposure at hourly volumes beyond 1300 vehicles/h almost reached asymptote i.e., the animal was at risk of collision for the entire traversing duration.

Change in traffic volume and traffic flow speeds had the strongest influence on $P_{h}$ (Fig. 6). From the sensitivity analysis we found that AVC probability was positively influenced by length of the vehicle (PIC $0.032 ; 95 \%$ CI $0.02-0.039$ ), and negatively influenced by velocity of vehicles (PIC $-0.093 ; 95 \% \mathrm{CI}-0.11$ to -0.07 ). We found no significant contribution of width of the vehicle (PIC -0.015 ; 95\% CI $-0.016-0.047$ ). Traffic flow speeds decreased with increasing traffic volume and this change in speeds tended to increase $P_{h}$ across all traffic heterogeneity scenarios on both lane types (Supplementary Fig. S1).

Influence of animal activity on AVC risk. We photo-captured a total of 6043 photographs across 23 mammals, and 3624 images of our study species. The total sampling effort was 3024 camera-days at 216 camera trapping locations. Tiger and leopard were not considered for this analysis owing to low number of captures ( $n=12$ and $n=1$ respectively) and larger home ranges as compared to the trapping area.

We used species-specific hourly AVC probabilities and corresponding hourly detection probabilities calculated from captures of chital $(n=802)$, gaur $(n=34)$, sambar $(n=21)$ and wild pig $(n=79)$ to calculate hourly AVC risks for the four study species. We found differential effects of traffic and animal activity on AVC risk (Fig. 7). At peak traffic hours, AVC risk for wild pig was higher than for chital on both 2-lane and 4-lane roads. For sambar and gaur, there was no risk of AVC during peak traffic hour because their activities near the road did not coincide with traffic activity at peak traffic hour. The peak activity of chital during evening hours coincided with a traffic activity peak, and thus the AVC risk for chital was expected to be highest during this time, on both 2-lane and 4-lane road. Moreover, the activities of sambar and gaur showed lesser overlap with traffic activity while chital and wild pig had comparatively higher overlap (Supplementary Table S4).

\section{Discussion}

We demonstrated the applicability of the traversability model to determine species-specific AVC probabilities and AVC risk across different traffic heterogeneity and traffic volume scenarios. We found that slow moving animals and animals with large group sizes were at higher risk of AVC as a consequence of greater time required to traverse roads. Further, AVC probability is expected to be greater on wider roads, particularly high traffic roads with predominantly heavy vehicles.

Among the six study species, lowest AVC probabilities were observed for tiger and leopard, primarily because these are solitary fast moving species. Body size had negligible effect on AVC probability ${ }^{23}$, but increase in group 
a

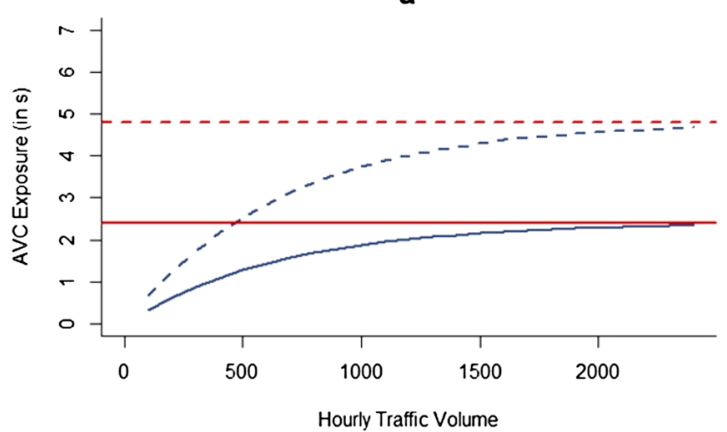

C

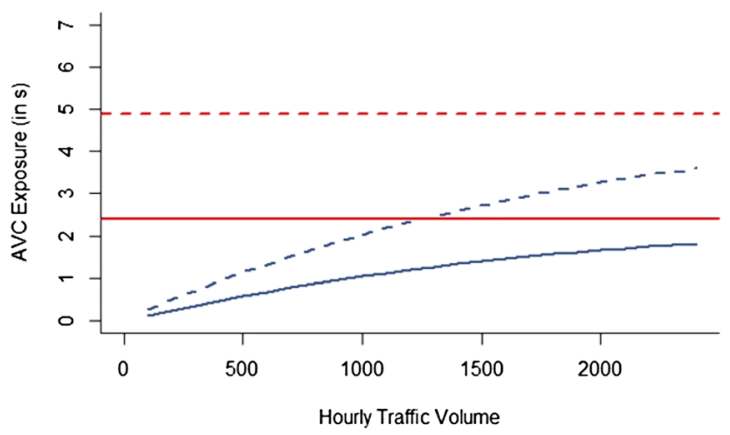

e

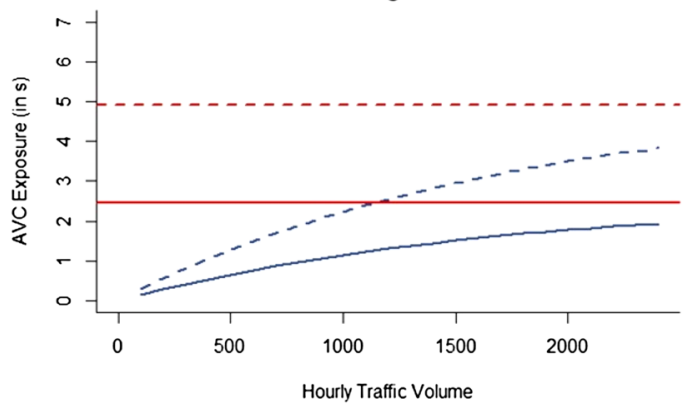

b

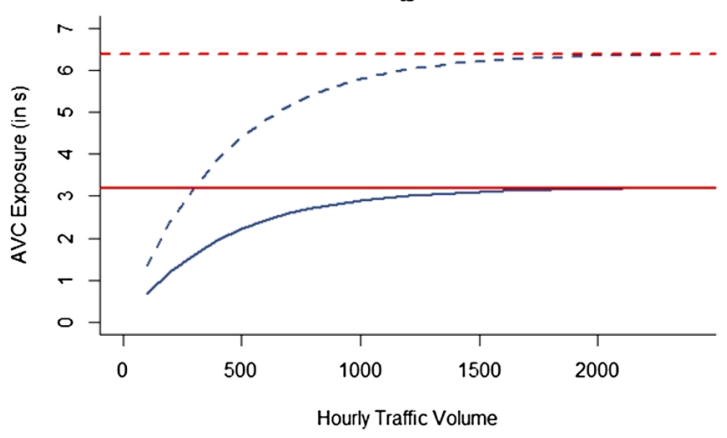

d

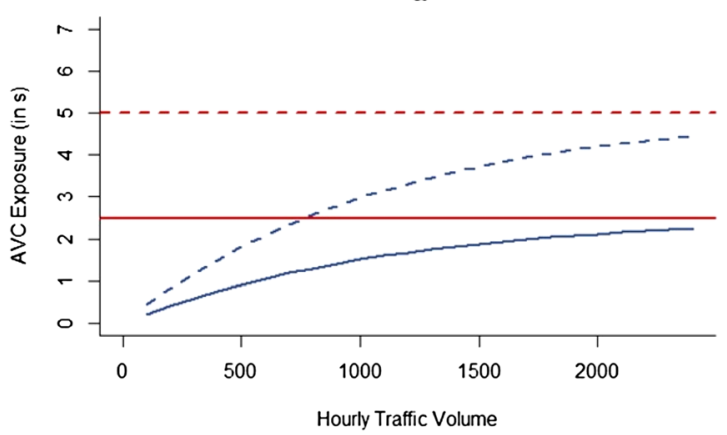

f

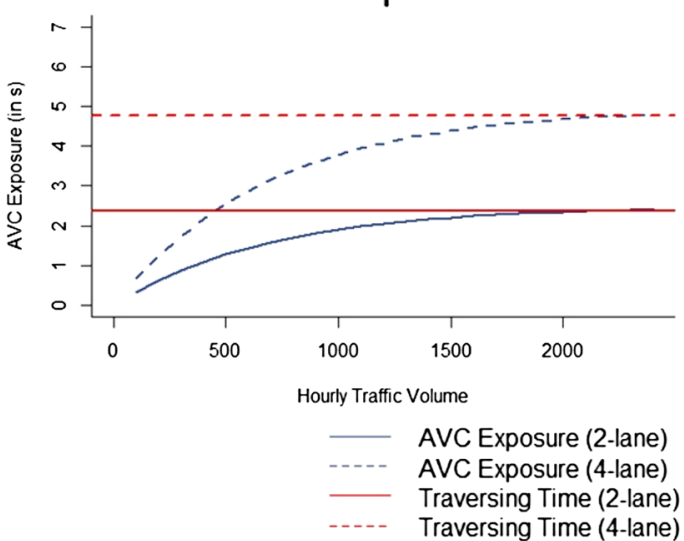

Figure 5. AVC exposure (blue curves; in seconds) of (a) chital, (b) gaur, (c) leopard, (d) sambar, (e) tiger, and (f) wild pig, a function of the duration of time an animal needs to traverse different widths of roads (red lines) and the Animal Vehicle Collision (AVC) probability under the hourly traffic volume at that time. Figure created using $\mathrm{R}^{45}$ version 3.6 (https://www.rstudio.com/).

size increased the probability resulting in higher AVC probabilities for group living species. Among social species, lower group size of sambar translated to lower AVC probability than chital and wild pig, despite having similar maximum running speeds. Group size of gaur was similar to that of wild pig; yet gaur had the highest AVC probabilities across all heterogeneity scenarios as a result of its low running speed.

Mammals with low reproductive rates and high mobility, like carnivores show more negative responses to roads and traffic ${ }^{34}$, and carnivore movement is affected more than herbivores ${ }^{35,36}$ at high traffic volumes. Even though both carnivores in our study had the lowest AVC probabilities among all study species, they may not attempt crossing wider roads at high traffic volumes which could ultimately present a barrier to their movement ${ }^{19}$.

The AVC probability across different heterogeneity scenarios showed variability, largely as a consequence of the speeds of traffic flow. Results show that the highest AVC probabilities occurred for traffic compositions with higher proportions of heavy vehicles. Since heavy vehicles impede the cumulative traffic flow speed, the probability of occurrence of a vehicle at any point on the road increases, consequently translating to higher probabilities of hit mostly for slow-moving and group living animals. On the contrary, in a traffic flow with high flow speed, there is greater inter-vehicular distance available which translates to higher probability of an animal to cross the road without encountering a vehicle. This finding has implications for speed-regulating mitigation measures like 

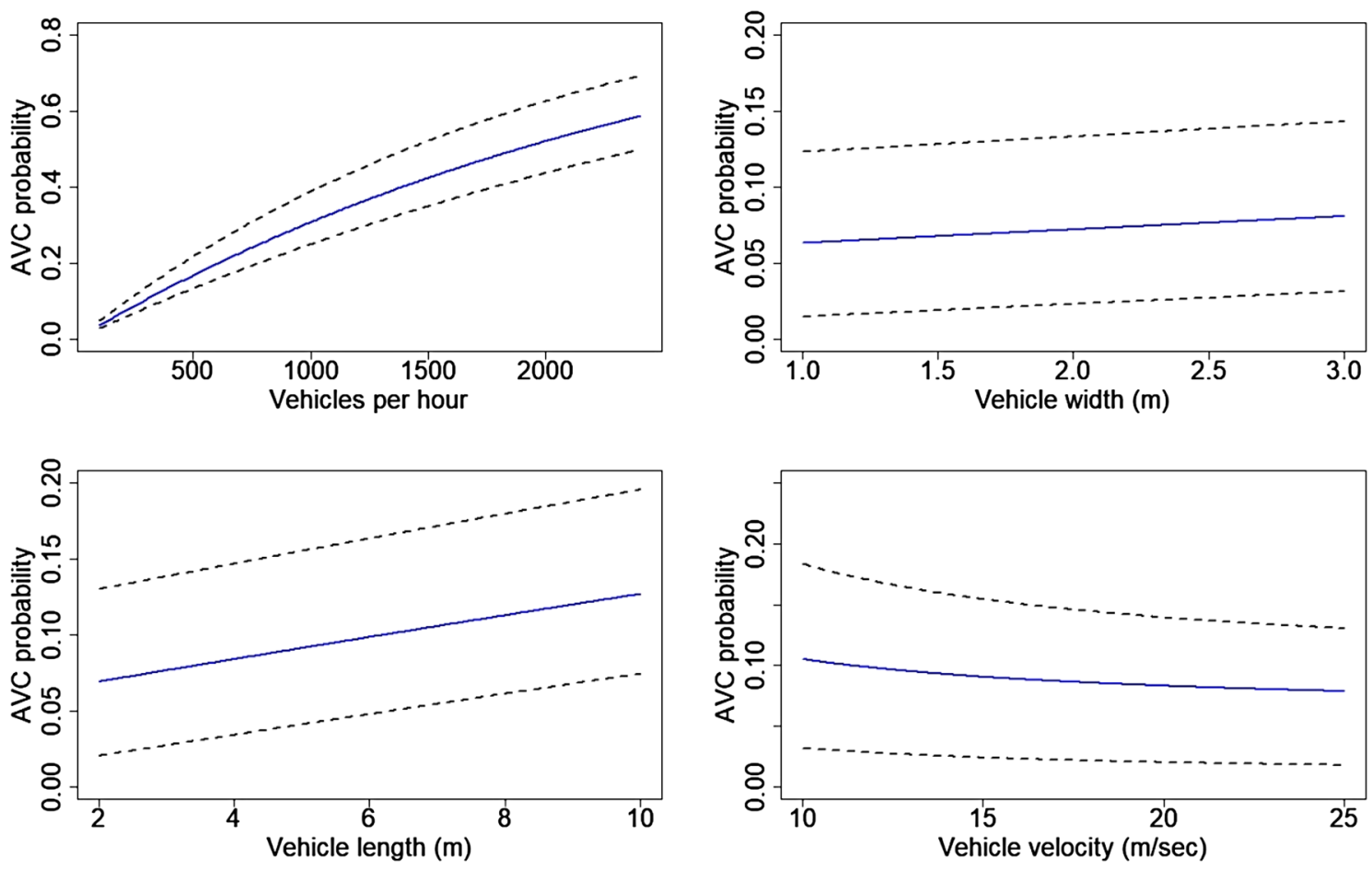

Figure 6. Relative effects of traffic characteristics on Animal Vehicle Collision (AVC) probability. To calculate the change in AVC probability with unit change in the target variables, the mean values of other variables were plugged into Eq. (1). Dotted lines indicate $95 \%$ confidence intervals around coefficient estimates. Figure created using $\mathrm{R}^{45}$ version 3.6 (https://www.rstudio.com/).
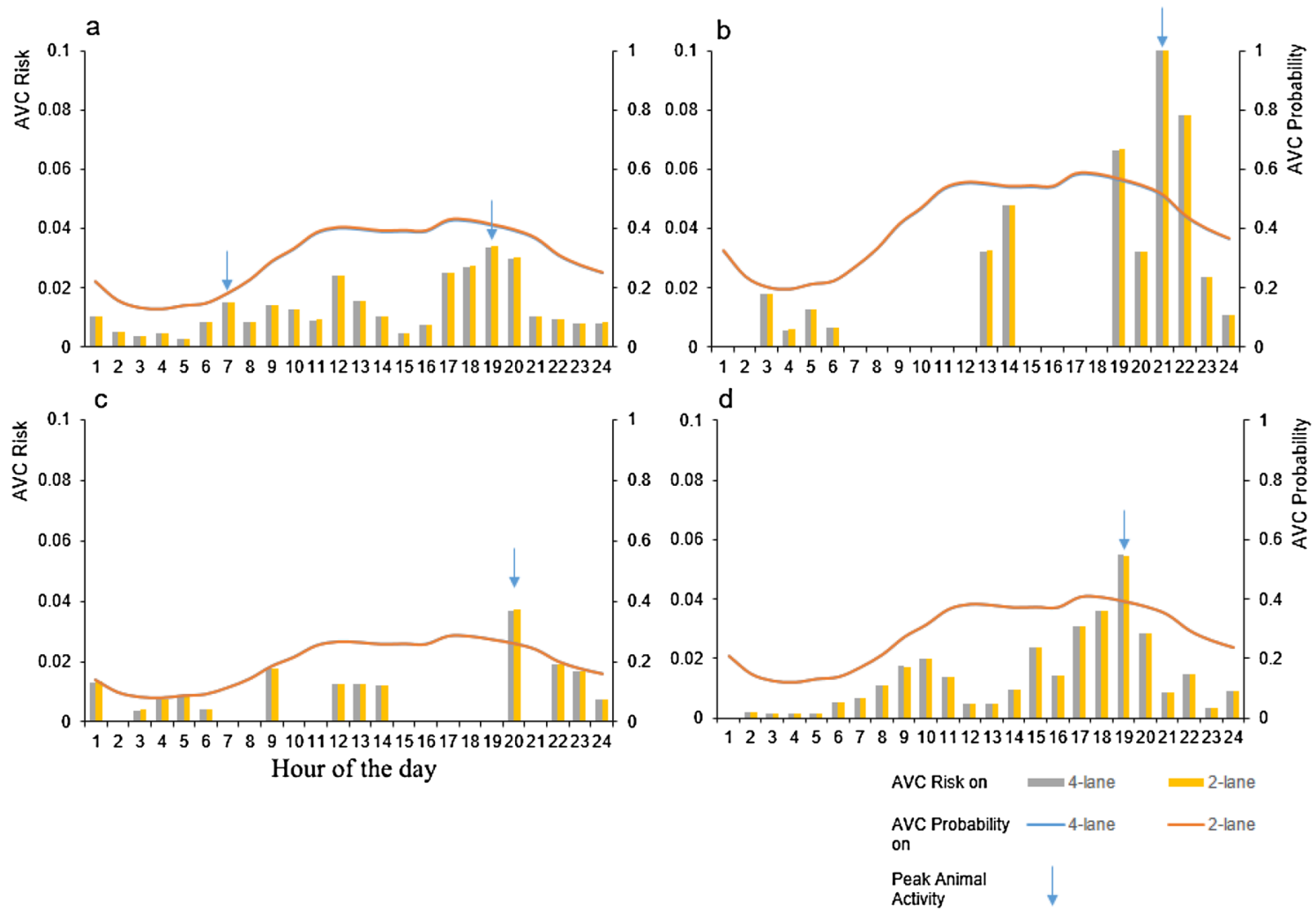

Figure 7. Animal Vehicle Collision (AVC) risk (yellow and grey bars) and AVC probability (red and blue curves) across $24 \mathrm{~h}$ for (a) chital, (b) gaur, (c) sambar and (d) wild pig. The AVC risk plotted on the secondary axis was computed as the product of AVC probability and hourly detection probability (used as a proxy for animal activity). Figure created using $\mathrm{R}^{45}$ version 3.6 (https://www.rstudio.com/). 
speed breakers and rumble strips that can potentially decrease inter-vehicular distances at medium-high traffic volumes, leading to creation of a barrier-like situation for animal movement.

At higher traffic volumes the barrier effect sets in due to continuous flow of traffic, where road crossing by animals may not occur. Thus higher traffic volumes would result in a barrier-like situation because of avoidance of animals at high traffic segments ${ }^{6,7}$ reducing the number of attempted crossings by wildlife. This avoidance would reflect as low roadkill counts on high traffic roads ${ }^{22}$.

Even though AVC probabilities on wide road segments were similar to probabilities on narrow roads, the exposure of an individual/animal group to AVC while traversing a 4-lane segment was found to be almost double than the exposure on 2-lane segment. This risk of exposure was highest for species with large group sizes. Greater exposure on 4-lane roads at moderate traffic levels could cause more roadkill than on 2-lane roads, while on 2-lane roads the same traffic levels could become a barrier to animal movement.

The traversability model ${ }^{37}$ did not consider animal activity near roads. For an animal-vehicle collision to take place, an animal and a vehicle must co-occur on the road. We accounted for this by using animal activities near the road as a proxy for the probability of an animal encountering a road. Creation of edge habitats by linear intrusions like roads facilitate the use of such habitats by some ungulate species. Consequently for edge-tolerant species like chital and wild pig $^{38}$ that were found to use road-forest edges, hourly roadkill risk is a function of hourly traffic volume since their activities near the road coincide with peak hours of traffic activity (Chital and Traffic Overlap Coefficient Dhat $1=0.82$; Wild pig and Traffic Overlap Coefficient Dhat $1=0.82$ ). Hence use of roadside habitat by chital and wild pig, makes them more vulnerable to mortality effects. For gaur and sambar that are generally crepuscular and nocturnal species with low road-forest edge use, the roadkill risk is a direct consequence of its activity in the early morning or late evening hours (Supplementary Table S4).

At present, traffic on NH 44 may not present a barrier to movement of chital and wild pig as we frequently encounter chital and wild pig roadkill at present traffic volumes. Gaur and sambar, on the other hand, are more vulnerable to barrier effect through avoidance behaviour of roadside habitat that reflects a lower tolerance to traffic disturbance ${ }^{39,40}$.

As in the aforementioned studies ${ }^{8,23,37}$, the aim of the study is not to determine the actual number of mortalities, but to help determine high-risk roads, traffic compositions and species groups most vulnerable to collision and barrier effects. Our model defines a way to identify components of a road network most vulnerable to roadkill, and could be used to identify road network components requiring prioritised mitigation action. In the absence of data on animal movement near roads, the present approach using species traits and behaviour could help prioritise mitigation for species most vulnerable to collision with vehicles.

Our framework can help inform mitigation of AVC and barrier effects in two ways: by identifying existing and proposed roads in a network that are or may become barriers to animal movement because of present and projected traffic volume, and by informing measures on existing roads with no structural mitigation measures based on traffic and animal activity. This is important for developing economies with rapidly increasing traffic loads on existing unmitigated road networks.

For existing road networks, our approach could help identify roads that are vulnerable to high roadkill rates as a function of their traffic volume and traffic composition. Measures may include speed restrictions for traffic predominantly consisting of small vehicles, temporal limitations on heavy vehicles and construction of animal passages on high traffic multiple use roads. Other actions such as alternate road network alignments considering projected traffic growth, combined with additional information on animal corridors, species occurrence and animal activity, can inform future road developments at the landscape scale.

Planning mitigation measures in a rapidly expanding road network with multiple use roads and highly heterogeneous traffic has to be futuristic and strategic i.e., it should consider large-scale and long-term conservation needs. Under such conditions, traffic volume is a critical parameter that would inform landscape-level prioritization with respect to present and projected traffic loads. Accommodating increased traffic on existing roads versus building new roads is an ongoing debate-while it has been stated that accommodating increased traffic growth on existing roads would be less damaging ${ }^{33}$, threshold traffic volumes may reduce animal road crossing rates, and create barrier to animal movement ${ }^{39}$. Thus, including traffic growth projections while planning mitigation for new roads (planning mitigation structure types, rerouting) would make mitigation viable for the long-term.

\section{Methods}

Study area. We conducted our study on a $60 \mathrm{~km}$ segment of the NH 44 (previously NH 7) that straddles the Maharashtra-Madhya Pradesh interstate boundary (Fig. 8) in central India. The highway forms the North-South transportation corridor, connecting major Indian economic and urban centres. The study was conducted on a $16 \mathrm{~km}$ 4-lane segment passing through Pench Tiger Reserve, Maharashtra, and a $29 \mathrm{~km}$ 2-lane segment passing through Pench Tiger Reserve, Madhya Pradesh. The tiger reserves are part of the Central Indian Landscape, which is a priority tiger conservation unit ${ }^{41}$. The forest in the area is mostly of the moist and dry deciduous type $^{42}$. Tiger Panthera tigris, leopard Panthera pardus, sloth bear Melursus ursinus and wild dog Cuon alpinus are the major carnivores, and gaur Bos gaurus, chital or spotted deer Axis axis, sambar Rucervus unicolor, wild pig Sus scrofa, nilgai or blue bull Boselaphus tragocamelus, chausingha or four-horned antelope Tetracerus quadricornis are the major ungulate prey species found in the landscape. Tiger and leopard-the two apex predators, and gaur, spotted deer, sambar, and wild pig, common prey species of tiger and leopard were selected as the study species.

Influence of species traits on AVC probability. We modelled the probabilities of successful crossing or hit for different animal species based on the traversability model ${ }^{37}$. The model is based on the calculation of headway distributions in a traffic flow, i.e., the frequency of the distance between successive vehicles at a 


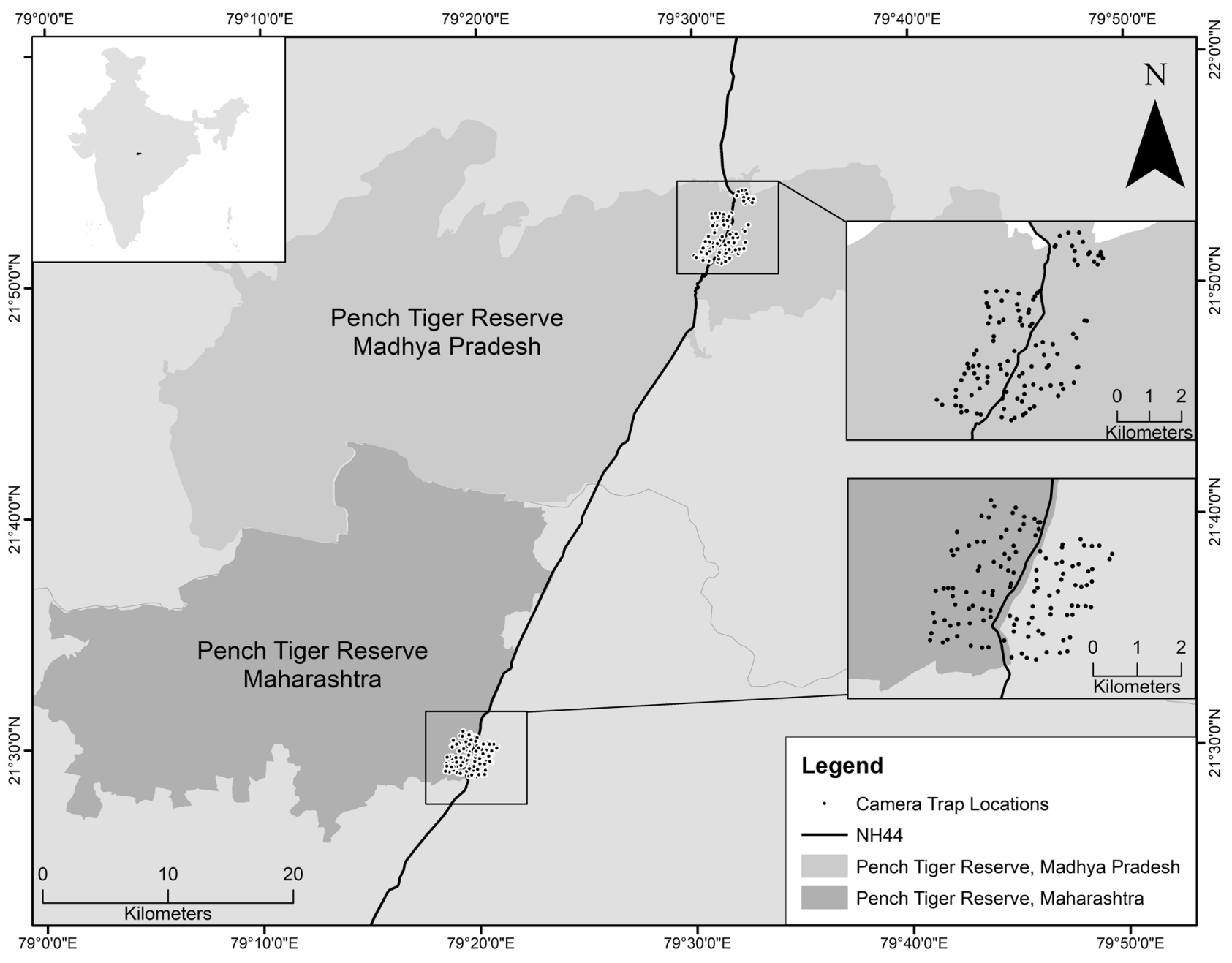

Figure 8. National Highway 44 passes through the Pench Tiger Reserves, Madhya Pradesh and Maharashtra. [Inset] Camera trapping locations on two forest stretches along NH 44. Map generated using ArcGIS $10.8^{59}$ (www.esri.com).

given cross-section, which is assumed to follow Poisson distribution ${ }^{43}$. The probability of successful crossing $\left(P_{a}\right)$ depends on the time ' $T$ ' (in seconds) during which the animal and vehicle are co-incident on a road, and depends on traffic, road and species characteristics. Therefore,

$$
P_{a}=e^{-\lambda\left(\frac{W_{c}+L_{a}}{V_{a}}+\frac{L_{c}+W_{a}}{V_{c}}\right)}
$$

where $W_{c}, L_{c}$ and $V_{c}$ are the width and length (in m), and speed of vehicles (in m/s), $W_{a}, L_{a}$ and $V_{a}$ are the width and length (in $\mathrm{m}$ ), and speed of animals (in $\mathrm{m} / \mathrm{s}$ ), and ' $\lambda$ ' is the traffic volume (in vehicles/s).

$W_{c}, L_{c}$ and $V_{c}$ (vehicle characteristics) were calculated for different traffic heterogeneity scenarios, and $W_{a}, L_{a}$ and $V_{a}$ (animal characteristics) were calculated for different study species.

The probability of hit or AVC probability $\left(P_{h}\right)$ was then calculated as

$$
P_{h}=1-P_{a} .
$$

The model assumes that traversing of roads by animals is 'blind' for animals in that they do not respond to the presence of vehicles (i.e. do not stop or turn around), and for drivers in that they do not respond to the presence of animals on the road by braking. Therefore, we define $P_{h}$ as the probability of hit of an animal that is attempting to cross the road, as we cannot account for the number of crossing attempts that translate into actual presence of animal on the road for an AVC to occur.

Sensitivity of $P_{h}$ to change in model parameters viz., traffic (vehicle length, vehicle width, vehicle speed and hourly volume) and animal characteristics (body length, width, speed and average group size) was calculated using package "pse" 44 in R version 3.65. Change in AVC probability with unit change in each model parameter was calculated at $95 \%$ confidence intervals while keeping other variables at mean values. We used uniform probability distribution for all the variables except length of animals, length of vehicles and velocity of vehicles for which we used normal probability distribution. We used 1000 bootstraps of the Latin hypercube sampling (LHS) to understand the effect of the variables and to estimate the uncertainty for evaluation of the confidence interval 


\begin{tabular}{|l|l|l|l|l|l|l|}
\hline Animal species & Average weight $(\mathbf{k g})$ & Body length $(\mathbf{m a x})(\mathbf{m})$ & Body width $(\mathbf{m})$ & Mean group size & Maximum running speed $(\mathbf{m} / \mathbf{s})$ & Traversing speed $(\mathbf{m} / \mathbf{s})$ \\
\hline Chital Axis axis & 65 & 1.55 & 0.6 & 8.15 & 17.49 & 2.91 \\
\hline Gaur Bos gaurus & 825 & 3.3 & 1 & 4.75 & 13.14 & 2.19 \\
\hline Leopard Panthera pardus & 49.25 & 2.43 & 0.4 & 1 & 17.17 & 2.86 \\
\hline Sambar Rusa unicolor & 202.5 & 2.1 & 0.8 & 2.85 & 16.82 & 2.80 \\
\hline Tiger Panthera tigris & 173.75 & 3.1 & 0.6 & 1 & 17.08 & 2.84 \\
\hline Wild pig Sus scrofa & 90 & 2 & 0.5 & 5.87 & 17.6 & 2.93 \\
\hline
\end{tabular}

Table 1. Species characteristics including morphometric data and behaviour used for calculation of animal vehicle collision probabilities.

and partial inclination coefficients (PIC). Confidence interval non-overlapping zero signifies a considerable effect of the variable and the sign of the PIC denotes the direction of the effect of the variable.

Road and traffic characteristics. We obtained traffic volume data for NH 44 from the regional Project Implementation Unit of the National Highway Authority of India for a period of 2 weeks during the study, and extracted the daily and hourly traffic patterns and heterogeneity viz., car/van, LCV (light commercial vehicle), bus/truck, MAV (multi-axle vehicle) and OSV (off-shore vehicle).

Traffic flow speeds were simulated at different hourly traffic volumes (100-2400 vehicles per hour) for present traffic heterogeneity using the traffic-simulation software VISSIM 11.00 Student Edition ${ }^{46}$. We simulated traffic flow on a road section or 'link' of $1 \mathrm{~km}$ on the VISSIM interface, and specified the width, number of lanes and direction of traffic flow. We set the road type as 'Freeway (free lane selection)', and number of lanes at 2 for 4 -lane road, and 1 for 2-lane road. For 4-lane road with a median, we generated average speed of vehicles on one side (2-lanes). We followed the same approach for 2-lane road, assuming that overtaking on undivided road did not take place. We set lane widths at $3.5 \mathrm{~m}^{47}$, and vehicle composition or heterogeneity as containing three major types of vehicles-car (categories car and LCVs were merged), bus/truck, and MAV (categories MAV and OSV were merged). The headways of the heterogeneous traffic flow were assumed to follow negative exponential distribution ${ }^{48}$, and the free flow speeds of different vehicle types was assumed to follow normal distribution ${ }^{49}$. All model parameters viz., driving behaviour characteristics, vehicle length and width and desired free-flow speed for each vehicle type (following Bains, Ponnu and Arkatkar ${ }^{50}$ ), and relative flow (proportion of vehicle type in traffic flow or heterogeneity) have been detailed in Supplementary Table S1.

We placed vehicle input points at the beginning of the link, and data collection points midway along the road, and specified the hourly traffic volume at each vehicle input point. The average harmonic speed of traffic flow at each traffic volume and free flow speeds of different traffic components were selected as data collection measurement attributes (outputs of the simulation). Each simulation was run for $600 \mathrm{~s}$ (10 min) with 20 replicates. Simulation resolution of 10 time steps/second was set to maximize speed data collection at data collection points.

Species characteristics. We obtained data on species morphometry viz., length, width ${ }^{51}$, and average group size ${ }^{51-55}$ for the six study species (chital, gaur, leopard, sambar, tiger and wild pig) (Table 1). To account for collective risk for group living species, the average group size was factored into the average length of animal ${ }^{23}$ in Eq. (1).

We calculated the maximum animal speeds from the equation for terrestrial animals (running) given by Hirt, Jetz, Rall and Brose ${ }^{56}$, based on average animal body weights 'M'.

$$
V_{\max }=25.5 M^{0.26}\left(1-e^{-22 M^{-0.6}}\right)
$$

During the study period, we recorded the walking speeds (in $\mathrm{m} / \mathrm{s}$ ) of the study animals in their natural habitats inside PTR, Maharashtra, to calculate the average moving speed. For each species, we averaged 14-20 observations of various walking speeds which was found to be close to $1 / 6$ th of the top running speed (Supplementary Table S2).

Influence of road and traffic characteristics on AVC probability. With respect to different traffic compositions in a traffic flow (in terms of types of vehicles) specified in Supplementary Table S1, traffic flow speeds for different heterogeneity scenarios namely $\mathrm{H}_{1}-\mathrm{H}_{9}$ were simulated using VISSIM for hourly traffic volumes ranging from 100 to 2400 vehicles per hour (as defined in Section A of Methods under 'Road and traffic characteristics').

We calculated AVC probability $\left(P_{h}\right)$ under different scenarios of traffic heterogeneity on 2-lane and 4-lane sections of the road using Eq. (1). The exposure risk in seconds i.e., the time on the road for which an animal would be vulnerable to collision as a function of road width and $P_{h}$ was also calculated.

Influence of animal activity on AVC risk. The behaviour of animals, in terms of activity patterns in the vicinity of roads, was incorporated into the model in the form of AVC risk, which is the AVC probability under a specific hourly traffic volume for a species, multiplied by the activity (hourly detection probability) of the animal near the road. 
To quantify animal activity, we deployed motion-activated ScoutGuard Long Range Incandescent Flash Trail Cameras (https://www.scoutguard.com.au/) in two forest segments ( $8 \times 5 \mathrm{sq}$. km each) along NH 44 in PTR, Maharashtra and PTR, Madhya Pradesh (Fig. 8). The selected forest segments were intersected by the highway-a $5 \mathrm{~km}$ long 2-lane section through PTR, Madhya Pradesh, and a $5 \mathrm{~km}$ long 4-lane section through PTR, Maharashtra, Both forest segments were divided into $400 \times 400 \mathrm{~m}$ grids on both sides of the road, and were similar in terms of vegetation and habitat type, hourly traffic volume, traffic load, and animal densities. Single-sided camera traps were deployed along forest trails and dirt roads in both sections in two phases during July-August 2017, at increasing distances from the highway. The hourly capture rates of animals calculated from camera traps within $0-400 \mathrm{~m}$ from the road $(\mathrm{n}=47)$ were used to calculate the roadkill risk under present traffic heterogeneity conditions, assuming that animals captured at this distance were most likely to encounter roads. Roadkill risk was calculated by multiplying hourly capture rates, an indicator of time spent close to road (activity), with the probability of being hit by a vehicle (AVC probability or $P_{h}$ ). Overlap of animal and traffic activity was calculated using functions 'overlapEst' and 'bootEst' in package 'overlap ${ }^{57}$ in $\mathrm{R}$ version $3.6^{45}$.

Received: 1 May 2020; Accepted: 20 October 2020

Published online: 03 November 2020

\section{References}

1. Laurance, W. F., Goosem, M. \& Laurance, S. G. W. Impacts of roads and linear clearings on tropical forests. Trends Ecol. Evol. 24, 659-669. https://doi.org/10.1016/j.tree.2009.06.009 (2009).

2. van der Ree, R., Smith, D. J. \& Grilo, C. The ecological effects of linear infrastructure and traffic: challenges and opportunities of rapid global growth. In Handbook of Road Ecology (eds van der Ree, R. et al.) 1-9 (Wiley Blackwell, New York, 2015).

3. Trombulak, S. C. \& Frissel, C. A. Review of ecological effects of roads on terrestrial and aquatic communities. Conserv. Biol. 14, 18-30. https://doi.org/10.1046/j.1523-1739.2000.99084.x (2001).

4. Bujoczek, M., Ciach, M. \& Yosef, R. Road-kills affect avian population quality. Biol. Conserv. 144, 1036-1039. https://doi. org/10.1016/j.biocon.2010.12.022 (2011).

5. Erritzoe, J., Mazgajski, T. D. \& Rejt, Ł. Bird casualties on european roads-a review. Acta Ornithol. 38, 77-93 (2003).

6. Baker, P. J., Dowding, C. V., Molony, S. E., White, P. C. L. \& Harris, S. Activity patterns of urban red foxes (Vulpes vulpes) reduces the risk of traffic-induced mortality. Behav. Ecol. 18, 716-724. https://doi.org/10.1093/beheco/arm035 (2007).

7. Thurjfell, H., Spong, G., Olsson, M. \& Ericsson, G. Avoidance of high traffic levels results in lower risk of wild boar-vehicle accidents. Landsc. Urban Plan. 133, 98-104 (2015).

8. Jaarsma, C. F., van Langevelde, F., Baveco, J. M., van Eupen, M. \& Arisz, J. Model for rural transportation planning considering simulating mobility and traffic kills in the badger Meles meles. Ecol. Inform. 2, 73-82 (2007).

9. Clarke, G. P., White, P. C. L. \& Harris, S. Effects of roads on badger Meles meles populations in south-west England. Biol. Conserv. 86, 117-124 (1998).

10. Blom, A., van Zalinge, R., Heitkonig, I. M. A. \& Prins, H. H. T. Factors influencing the distribution of large mammals within a protected central African forest. Oryx 39, 381-388 (2005).

11. Leblond, M., Dussault, C. \& Ouellet, J.-P. Avoidance of roads by large herbivores and its relation to disturbance intensity. J. Zool. 289, 32-40. https://doi.org/10.1111/j.1469-7998.2012.00959.x (2013).

12. Lande, R. Genetics and demography in biological conservation. Science 241, 1455-1460 (1988).

13. Shepard, D. B., Kuhns, A. R., Dreslik, M. J. \& Philips, C. A. Roads as barriers to animal movement in fragmented landscapes. Anim. Conserv. 11, 288-296. https://doi.org/10.1111/j.1469-1795.2008.00183.x (2008).

14. Ibisch, P. L. et al. A global map of roadless areas and their conservation status. Science 354, 1423-1427. https://doi.org/10.1126/ science.aaf7166 (2016).

15. Sperling, D. \& Gordon, D. Two billion cars: transforming a culture. TR News. 259, 3-9 (2008).

16. Ferreras, P., Aldama, J. J., Beltran, J. F. \& Delibes, M. Rates and causes of mortality in a fragmented population of Iberia lynx Felis pardina Temminck, 1824. Biol. Conserv. 61, 197-202 (1992).

17. Conard, J. M. \& Gipson, P. S. Spatial and seasonal variation in wildlife-vehicle collisions. Prairie Nat. 38, 251-260 (2006).

18. Giffney, R. A., Russell, T. \& Kohen, J. L. Age of road-killed common brushtail possums (Trichosurus vulpecula) and common ringtail possums (Pseudocheirus peregrinus) in an urban environment. Aust. Mammal. 31, 137-142 (2009).

19. Schwab, A. C. \& Zandbergen, P. A. Vehicle-related mortality and road crossing behavior of the Florida panther. Appl. Geogr. 31, 859-870 (2011).

20. Newmark, W. D., Boshe, J. I., Sariko, H. I. \& Makumbule, G. K. Effects of a highway on large mammals in Mikumi National Park Tanzania. Afr. J. Ecol. 34, 15-31 (1996).

21. Barrientos, R. \& Bolonio, L. The presence of rabbits adjacent to roads increases polecat road mortality. Biodivers. Conserv. 18, 405-418. https://doi.org/10.1007/s10531-008-9499-9 (2009).

22. Kusta, T., Keken, Z., Jezek, M., Hola, M. \& Smid, P. The effect of traffic intensity and animal activity on probability of ungulatevehicle collisions in the Czech Republic. Saf. Sci. 91, 105-113. https://doi.org/10.1016/j.ssci.2016.08.002 (2017).

23. Langevelde, F. \& Jaarsma, C. F. Using traffic flow theory to model traffic mortality in mammals. Landsc. Ecol. 19, 895-907 (2004).

24. Hubbard, M. W., Danielson, B. J. \& Schmitz, R. A. Factors influencing the location of deer-vehicle accidents in Iowa. J. Wildl. Manag. 64, 707-712 (2000).

25. Seiler, A. Predicting locations of moose-vehicle collisions in Sweden. J. Appl. Ecol. 42, 371-382. https://doi.org/10.111 1/j.1365-2664.2005.01013.x (2005).

26. Orlowski, G. \& Nowak, L. Factors influencing mammal roadkills in the agricultural landscape of south-western Poland. Pol. J. Ecol. 54, 283-294 (2006).

27. D’Amico, M., Periquet, S., Roman, J. \& Revilla, E. Road avoidance responses determine the impact of heterogeneous road networks at a regional scale. J. Appl. Ecol. 53(1), 181-190. https://doi.org/10.1111/1365-2664.12572 (2015).

28. Brody, A. J. \& Pelton, M. R. Effects of roads on black bear movements in western North Carolina. Wildl. Soc. Bull. 17, 5-10 (1989).

29. Dyer, S. J., O’Neill, J. P., Wasel, S. M. \& Boutin, S. Quantifying barrier effects of roads and seismic lines on movement of female woodland caribou in northeastern Alberta. Can. J. Zool. 80, 839-845 (2002).

30. Rico, A., Kindlmann, P. \& Sedlacek, F. Barrier effect of roads on movement of small mammals. Folia Zool. 56(1), 1-12 (2007).

31. McCown, W., Kubilis, P., Eason, T. \& Scheik, B. Black bear movements and habitat use relative to roads in Ocala National Forest. Final Report. Florida Department of Transportation Contract BD-016. Florida Fish and Wildlife Conservation Commission, Tallahassee, Florida, USA. (2004). accessed 28 Nov 2019; https://www.researchgate.net/publication/232668218_Effect_of_traff ic_volume_on_American_black_bears_in_central_Florida_USA. 
32. Visintin, C., van der Ree, R. \& McCarthy, M. A. A simple framework for a complex problem? Predicting wildlife-vehicle collisions. Ecol. Evol. 6, 6409-6421. https://doi.org/10.1002/ece3.2306 (2016).

33. Rhodes, J. R., Lunney, D., Callaghan, J. \& McAlpine, C. A. A few large roads or many small ones? How to accommodate growth in vehicle number to minimise impacts on wildlife. PLoS ONE 9(3), e91093 (2014).

34. Rytwinksi, T. \& Fahrig, L. Do species life history traits explain population responses to roads? A meta-analysis. Biol. Conserv. 147, 87-98. https://doi.org/10.1016/j.biocon.2011.11.023 (2012).

35. Alexander, S. M., Waters, N. M. \& Paquet, P. C. Traffic volume and highway permeability for a mammalian community in the Canadian Rocky Mountains. Can. Geogr. 49, 321-331 (2005).

36. Baigas, P. E., Squires, J. R., Olson, L. E., Ivan, J. S. \& Roberts, E. K. Using environmental features to model highway crossing behaviour of Canada lynx in the southern Rocky Mountains. Landsc. Urban Plan. 157, 200-213. https://doi.org/10.1016/j.landu rbplan.2016.06.007 (2017).

37. Jaarsma, C. F., van Langevelde, F. \& Botma, H. Flattened fauna and mitigation: traffic victims related to road, traffic, vehicle, and species characteristics. Transp. Res. Part D 11, 264-276. https://doi.org/10.1016/j.trd.2006.05.001 (2006).

38. Sunquist, M., Karanth, K. U. \& Sunquist, F. Ecology, behaviour and resilience of the tiger and its conservation needs. In Riding the Tiger: Tiger Conservation in Human Dominated Landscapes (eds Seidensticker, J. et al.) 1-3 (Cambridge University Press, Cambridge, 1999).

39. Gagnon, J. W., Theimer, T. C., Dodd, N. L., Boe, S. \& Schweinsburg, R. E. Traffic volume alters elk distribution and highway crossings in Arizona. J. Wildl. Manag. 71, 2318-2323. https://doi.org/10.2193/2006-224 (2006).

40. Jacobson, S. L., Bliss-Ketchum, L. L., de Rivera, C. E. \& Smith, W. P. A behaviour-based framework for assessing barrier effects to wildlife from vehicle traffic volume 1. Ecosphere 7, 1-15 (2016).

41. Jhala. Y. V., Qureshi, Q. \& Gopal, R. (eds.). The status of tigers, co-predators \& prey in India 2014. National Tiger Conservation Authority, New Delhi \& Wildlife Institute of India, Dehradun TR2015/021. (2015).

42. Champion, H. G. \& Seth, S. K. A Revised Survey of the Forest Types of India (Manager of Publications Govt. of India, New Delhi, 1968).

43. Haight, F. A. Mathematical Theories of Traffic Flow (Academic Press, London, 1963).

44. Chalom, A., \& de Prado, P. I. K. L. pse: Parameter Space Exploration with Latin Hypercubes. R package version 0.4.7. (2017). accessed 14 Sept 2019; https://CRAN.R-project.org/package=pse

45. R Studio Team. RStudio: Integrated Development for R. RStudio, PBC, Boston, MA. (2016). accessed 17 Mar 2019; https://www. rstudio.com/

46. Fellendorf, M. \& Vortisch, P. Microscopic Traffic Flow Simulator VISSIM. In Fundamentals of Traffic Simulation. International Series in Operations Research and Management Science (ed. Barcelo, J.) 63-93 (Springer, Berlin, 2010). https://doi. org/10.1007/978-1-4419-6142-6_2.

47. The Indian Roads Congress. Two-Laning of Highways Through Public Private Partnership: Manual of Specifications \& Standards. Secretariat for the Committee on Infrastructure Planning Commission, Yojana Bhavan, Parliament Street, New Delhi. (2010). accessed 12 July 2019; https://niti.gov.in/planningcommission.gov.in/docs/sectors/ppp_report/reports_guidelines/Manuals\%20 of $\% 20$ Standards\%20and\%20Specifications/Manual\%20of\%20Specifications\%20\&\%20Standards\%20for\%20Two-laning\%20of\%20 Highways.pdf

48. Arasan, V. T. \& Koshy, R. Z. Headway distribution of heterogeneous traffic on urban arterials. J. Inst. Eng. (India) 84, 210-215 (2003).

49. Velmurugan, S., Errampalli, M., Ravinder, K., Sitaramanjaneyulu, K. \& Gangopadhyay, S. Critical evaluation of roadway capacity of multi-lane high speed corridors under heterogeneous traffic conditions through traditional and microscopic simulation models. Journal of Indian Roads Congress (October-December 2010) 235-264 (2010). accessed 23 Mar 2019; https://www.crridom.gov.in/

50. Bains, M. S., Ponnu, B. \& Arkatkar, S. S. Modeling of traffic flow on Indian expressways using simulation technique. Procedia Soc. Behav. Sci. 43, 475-493. https://doi.org/10.1016/j.sbspro.2012.04.121 (2012).

51. Menon, V. Indian Mammals: A Field Guide (Hechette India, Gurugram, 2014).

52. Biswas, S. \& Sankar, K. Prey abundance and food habit of tigers (Panthera tigris tigris) in Pench National Park, Madhya Pradesh India. J. Zool. 256, 411-420. https://doi.org/10.1017/S0952836902000456 (2002).

53. Majumder, A. Prey Selection, Food Habits and Population Structure of Sympatric Carnivores: Tiger Panthera tigris tigris (L.), Leopard Panthera pardus (L.) and Dhole Cuon alpinus (Pallas) in Pench Tiger Reserve, Madhya Pradesh (India) (Saurashtra University, Rajkot, 2011).

54. Johnsingh, A. J. T. \& Manjrekar, N. (eds) Mammals of South Asia (Universities Press, Hyderabad, 2015).

55. Wildlife Institute of India. Pench Tiger Reserve project: Final report. (Wildlife Institute of India, Dehradun, 2016).

56. Hirt, M. R., Jetz, W., Rall, B. C. \& Brose, U. A general scaling law reveals why the largest animals are not the fastest. Nat. Ecol. Evol. 1, 1116-1122 (2017)

57. Ridout, M. \& Linkie, M. Estimating overlap of daily activity patterns from camera trap data. J. Agric. Biol. Environ. Stat. 14, 322-337 (2009).

58. Sarkar, D. Lattice: Multivariate Data Visualization with R. (2008). Springer, New York. ISBN 978-0-387-75968-5. accessed 25 Mar 2019; https://lmdvr.r-forge.r-project.org/.

59. ESRI. ArcGIS Desktop: Release 10.8. Redlands, CA: Environmental Systems Research Institute. (2020). accessed 12 Jan 2019; www. esri.com.

\section{Acknowledgements}

The authors thank the National Tiger Conservation Authority and Maharashtra Forest Department for funding the research project, and the state forest departments of Madhya Pradesh and Maharashtra for logistic support for fieldwork. We acknowledge support and encouragement from Director, Dean and Research Coordinator WII, and Member Secretary, National Tiger Conservation Authority, and Chief Wildlife Warden, Maharashtra Forest Department.

\section{Author contributions}

B.H. conceived the idea, B.H. and A.S. designed methodology; A.S. collected the data; A.S. and N.C. analysed the data; A.S. and B.H. led the writing of the manuscript. All authors contributed critically to the drafts and gave final approval for publication.

\section{Competing interests}

The authors declare no competing interests. 


\section{Additional information}

Supplementary information is available for this paper at https://doi.org/10.1038/s41598-020-75810-2.

Correspondence and requests for materials should be addressed to B.H.

Reprints and permissions information is available at www.nature.com/reprints.

Publisher's note Springer Nature remains neutral with regard to jurisdictional claims in published maps and institutional affiliations.

Open Access This article is licensed under a Creative Commons Attribution 4.0 International License, which permits use, sharing, adaptation, distribution and reproduction in any medium or format, as long as you give appropriate credit to the original author(s) and the source, provide a link to the Creative Commons licence, and indicate if changes were made. The images or other third party material in this article are included in the article's Creative Commons licence, unless indicated otherwise in a credit line to the material. If material is not included in the article's Creative Commons licence and your intended use is not permitted by statutory regulation or exceeds the permitted use, you will need to obtain permission directly from the copyright holder. To view a copy of this licence, visit http://creativecommons.org/licenses/by/4.0/.

(c) The Author(s) 2020 